\title{
Oral premedication in children: A randomized study of a combination of oral midazolam, ketamine with atropine vs midazolam and atropine vs ketamine and atropine
}

\author{
Ranjan Ramakrishna ${ }^{1}$, Hemanth $\mathrm{KJ}^{2}$, Sunil $\mathrm{BV}^{3, *}$, Neeta $\mathrm{S}^{4}$, Sonal Bhat ${ }^{5}$ \\ ${ }^{1,3}$ Associate Professor, ${ }^{2}$ Junior Resident, ${ }^{4}$ Assistant Professor, ${ }^{\mathbf{5}}$ Associate Professor, Dept. of Anesthesiology, Kasturba Medical \\ College, Mangalore, Manipal Academy of Higher Education, Mangaluru, Karnataka, India
}

*Corresponding Author:

Email: drsunilbv@gmail.com

Received: $26^{\text {th }}$ October, 2017

Accepted: $23^{\text {rd }}$ November, 2017

\begin{abstract}
Introduction: Premedication is widely used in pediatric anesthesia in order to provide sedation and anxiolysis. Aim of the study was to compare the effectiveness of combination of low dose oral midazolam and ketamine with oral midazolam or oral ketamine as premedication.

Materials and Methods: 150 childrens between ages 2 and 10 were divided into 3 groups of 50 members each. They received either combination of oral midazolam $0.5 \mathrm{mg} / \mathrm{kg}$ and oral ketamine $3 \mathrm{mg} / \mathrm{kg}$ or oral midazolam $0.5 \mathrm{mg} / \mathrm{kg}$ or oral ketamine $6 \mathrm{mg}$ $/ \mathrm{kg}$ as pre medication. Premedication was given 30 minutes before the induction of anesthesia. Patients also received oral atropine $0.02 \mathrm{mg} / \mathrm{kg}$ along with the study drug. Sedation and anxiolysis were assessed before giving premedication and at an interval of 10 minutes, 20 minutes and 30 minutes after premedication. Behavior at separation from parents and acceptance or response to venipuncture was also assessed at the end of 30 minutes. Statistical analysis was performed using SSPE computer software version 16. Groups are compared using chi square tests.

Result: We found that oral combination of midazolam $0.5 \mathrm{mg} / \mathrm{kg}$ and ketamine $3 \mathrm{mg} / \mathrm{kg}$ with atropine $0.02 \mathrm{mg} / \mathrm{kg}$ offered better sedation [96\% children], anxiolysis [76\% children], acceptance of parentral separation [80\% children] and comfortable venous cannulation [ $84 \%$ children]. We conclude that Combination of oral ketamine, midazolam and atropine is a superior premedicating agent than using these drugs individually
\end{abstract}

Keywords: Ketamine, Midazolam, Premedication, Pediatric.

\section{Introduction}

Fear of surgery and anxiety will be present in both parents as well as children. An ideal premedication should relieve anxiety, facilitate parenteral separation, acceptance of IV cannula and face mask. Postanaesthesia behavioral changes in children may be related to stressful hospital experiences. Its Incidence are higher in pre-school children. Most anesthesiologists use either parental presence or sedative premedication during induction. Separation from parents and induction of anesthesia are the impartent perioperative stress factors for children. ${ }^{1}$

A good premedication in pediatric age group should be easy to use, should have rapid onset and short duration of action with less side effects. Midazolam currently is the most commonly prescribed premedicant for pediatric patients. Several classes of drugs have been used successfully, including dissociative agents, barbiturates, opioids and alpha-2 receptor agonists. Midazolam and ketamine has been used extensively for pharmacological premedication, with adequate results. ${ }^{2-}$ 5 Combination of oral midazolam with ketamine was used to get better results with lesser side effects. ${ }^{6}$

Oral preparation has its own disadvantages like variable absorption, bioavailability, and being unpalatable, it is still better than needle pricks in children. Midazolam and ketamine is well absorbed when given by oral, nasal and rectal routes. Both starts acting after a time gap of 15- 20 minutes and produce a calm child for anaesthesia at the end 30 minutes. ${ }^{7-10}$

Midazolam is a water-soluble, short-acting benzodiazepine with rapid onset, short duration of action. It is an anxiolytic and sedative agent with minimal side effects.Ketamine is a phencyclidine derivative which acts on the n-methyl d-aspartate receptors and causes central dissociation of the cerebral cortex while providing amnesia and analgesia and applied for premedication in different studies. ${ }^{11,12}$

We conducted a prospective randomized control trail to know the efficacy of combination of small dose of ketamine $3 \mathrm{mg} / \mathrm{kg}$ with midazolam for premedication.

\section{Materials and Methods}

Study was approved by hospital ethics committee. 150 children between the age group 2 and 10 years were randomly selected for study. All children were scheduled for procedures lasting more than $30 \mathrm{~min}$.

Exclusion criteria: ASA III or higher, congenital heart defects ,hypo or hyperthyroidism or any other endocrinal disturbances, severe CNS dysfunction, severe liver and renal disease, risk of aspiration, severs systemic illness. 
Pre anaesthetic evaluation was done on the previous day of the scheduled procedure. Anaesthesia procedure to be undertaken was explained to the parents and informed consent was obtained from them. The patients were randomly divided in to 3 groups by sealed envelope technique. Oral preparation was prepared in syringes by the people involved in the study. Oral preparation was given by the anesthetist who was blinded to the study drug. Monitoring and data was collected by $\mathrm{O} T$ anesthetist who was blinded to the study drug.

Group MK: children in this group received combination of oral midazolam $0.5 \mathrm{mg} / \mathrm{kg}$ of body weight, ketamine $3 \mathrm{mg} / \mathrm{kg}$ of body weight with atropine $0.02 \mathrm{mg} / \mathrm{kg}$ mixed with honey, with total volume not more than $0.5 \mathrm{ml} / \mathrm{kg}$. Group M: children in this group received oral midazolam $0.5 \mathrm{mg} / \mathrm{kg}$ of body weight and atropine $0.02 \mathrm{mg} / \mathrm{kg}$ mixed with honey with total volume not more than $0.5 \mathrm{ml} / \mathrm{kg}$.

Group K: children in this group received oral ketamine $6 \mathrm{mg} / \mathrm{kg}$ of body weight and atropine $0.02 \mathrm{mg} / \mathrm{kg}$ mixed with honey with total volume not more than $0.5 \mathrm{ml} / \mathrm{kg}$.

Patients were premedicated thirty minutes prior to induction of anaesthesia. Oral premedication was given in the premedication room. Patients who refused to take the dose were excluded from the study. Monitoring was done using pulse oximetry in all patients. Sedation level and anxiolysis level were assessed before premedication and at an interval of $10 \mathrm{~min}, 20$ minutes and 30 minutes after premedication. Behavior at separation from parents and response to venipuncture was also assessed at the end of 30 minutes.

For assessing Sedation, anxiolysis, behavior at separation and acceptance of venipuncture separate scoring systems are used.

\section{Sedationlevel}

1. Alert and active

2. Awake

3. Drowsy but responds to verbal command

4. Asleep

\section{Anxiolysis level}

1. Panicky

2. Moaning

3. Composed

\section{Friendly}

\section{Behavior at separation}

1. Combative and clinging

2. Anxious

3. Calm

4. Sleeping

\section{Response to venipuncture}

1. Crying and uncooperative, not able to start IV line

2. Withdrawl for painful stimulus, but allows IV cannulation

3. Calm ,awake not crying, no withdrawal for IV cannulation

4. Asleep, no response to painful stimulus

\section{Statistical Analysis}

Statistical analysis was done using computer statistical software version SSPE 16. Data were expressed as either mean and standard deviation or numbers and percentages. Continuous covariates (age, height, weight) were compared using analysis of variance (ANOVA). Chi square test was used for calculating level of sedation, anxiolysis, behavior at separation and response to venipuncture. $\mathrm{P}<0.05$ was considered statistically significant.

\section{Results and Observation}

150 patients scheduled for various surgical procedures were included in this study.

They were divided into three groups:

Age distribution: Age of patients varied from 2-10 years in both groups, with a mean value of 5.44 in group MK, 5.18 in group $\mathrm{M}$ and 5.44 in group $\mathrm{K}$ and the $P$ value is 0.488 and is of no statistical significance.

Weight distribution: Weight of patients varied from 5$28 \mathrm{kgs}$ in both groups, with a mean value of 14.06 in group MK, 13.56 in group $\mathrm{M}$ and 14.44 in group $\mathrm{K}$ and the $\mathrm{P}$ value is 0.625 and is of no statistical significance.

Sex distribution: Group MK included 34 males \& 16 females. Group M included 36 males \&14 females. Group $\mathrm{K}$ included 35 males \& 15 females and $\mathrm{P}$ value is 0.663 and is of no statistical significance.

Table 1: Sedation level after premedication

\begin{tabular}{|l|c|c|c|c|}
\hline \multirow{2}{*}{ Sedation level } & \multicolumn{3}{|c|}{ Groups } & Total \\
\cline { 2 - 5 } & Group MK & Group M & Group K & \\
\hline Grade 1 Count & 2 & 12 & 14 & 28 \\
\% within group & $4.0 \%$ & $24.0 \%$ & $28.0 \%$ & $18.66 \%$ \\
\hline Grade II Count & 20 & 26 & 25 & 71 \\
\% within group & $40.0 \%$ & $52 \%$ & $50.0 \%$ & $47.33 \%$ \\
\hline Grade III Count & 26 & 12 & 11 & 49 \\
$\%$ within group & $52.0 \%$ & $24.0 \%$ & $22 \%$ & $32.68 \%$ \\
\hline Grade IV count & 2 & 0 & 0 & 2 \\
\% within group & $4.0 \%$ & $0 \%$ & $0 \%$ & $1.33 \%$ \\
\hline Total Count & 50 & 50 & 50 & 150 \\
\% within group & $100.0 \%$ & $100.0 \%$ & $100.0 \%$ & $100.0 \%$ \\
\hline
\end{tabular}


From the above table it is obvious that 48 patients [96\%] in group MK, 38 patients[76\%] in group $\mathrm{M}$ and 36 patients[72\%] in group $\mathrm{K}$ had acceptable levels of sedation which yielded a $\mathrm{P}$ value of $<0.002$, which is significant.

Table 2: Anxiolysis level after premedication

Chi-square $=24.987 \mathrm{P}=0.0005$

\begin{tabular}{|c|c|c|c|c|}
\hline \multirow{2}{*}{ Anxiolysis level } & \multicolumn{3}{|c|}{ Groups } & Total \\
\cline { 2 - 5 } & Group MK & Group M & Group K & \\
\hline Grade I Count & 0 & 4 & 6 & 10 \\
$\%$ within group & $0 \%$ & $8.0 \%$ & $12.0 \%$ & $6.67 \%$ \\
\hline Grade II Count & 12 & 30 & 30 & 72 \\
\%within group & $24.0 \%$ & $60.0 \%$ & $60.0 \%$ & $48.0 \%$ \\
\hline Grade III Count & 28 & 16 & 14 & 58 \\
\% within group & $56.0 \%$ & $32.0 \%$ & $28.0 \%$ & $38.66 \%$ \\
\hline Grade IV Count & 10 & 0 & 0 & 10 \\
\% with group & $20.0 \%$ & $0 \%$ & $0 \%$ & $6.67 \%$ \\
\hline Total Count & 50 & 50 & 50 & 150 \\
$\%$ within group & $100.0 \%$ & $100.0 \%$ & $100.0 \%$ & $100.0 \%$ \\
\hline
\end{tabular}

From the above table it is obvious that 38 patients [76\%] in group MK 16 patients [32\%] in group M and $14[28 \%$ ] in group $\mathrm{K}$ had acceptable levels of anxiolysis, which yielded a P value of $<0.0005$, which is very highly significant.

Table 3: Behavior at separation 30 after premedication

Chi-square $=21.731 \mathrm{P}=.0005$

\begin{tabular}{|c|c|c|c|c|}
\hline \multirow{2}{*}{$\begin{array}{c}\text { Behavior at } \\
\text { separation }\end{array}$} & \multicolumn{3}{|c|}{ Groups } & Total \\
\cline { 2 - 5 } & Group MK & Group M & Group K & \\
\hline Grade I Count & 0 & 6 & 8 & 14 \\
$\%$ within group & $0 \%$ & $12.0 \%$ & $16.0 \%$ & $9.33 \%$ \\
\hline Grade II Count & 10 & 22 & 29 & 61 \\
$\%$ within group & $20.0 \%$ & $44.0 \%$ & $58.0 \%$ & $40.67 \%$ \\
\hline Grade III Count & 30 & 22 & 13 & 65 \\
$\%$ within group & $60.0 \%$ & $44.0 \%$ & $26.0 \%$ & $43.33 .0 \%$ \\
\hline Grade IV Count & 10 & 0 & 0 & 10 \\
$\%$ within group & $20.0 \%$ & $0 \%$ & $0 \%$ & $6.66 \%$ \\
\hline Total Count & 50 & 50 & 50 & 150 \\
$\%$ Within group & $100.0 \%$ & $100 \%$ & $100.0 \%$ & $100.0 \%$ \\
\hline
\end{tabular}

40 patients [80\%] were calm and sleeping in group MK while only 22 [44\%] in group $\mathrm{M}$ and 13 [26\%] in group $\mathrm{K}$ were calm. The results yielded a $\mathrm{P}$ value of $<0.0005$ which is statistically very highly significant.

Table 4: Response to venepuncture

\begin{tabular}{|l|c|c|c|c|c|}
\hline Venepuncture & \multicolumn{3}{|c|}{ Groups } & Total \\
\cline { 2 - 6 } & Group MK & Group M & Group K & \\
\cline { 2 - 6 } & Grade 1 Count & 2 & 6 & 7 & 15 \\
\% within group & $4.0 \%$ & $12.0 \%$ & $14.0 \%$ & $10.0 \%$ \\
\cline { 2 - 6 } Grade II Count & 6 & 20 & 24 & 50 \\
\% within group & $12.0 \%$ & $40.0 \%$ & $48.0 \%$ & $33.33 \%$ \\
\hline Grade III Count & 28 & 24 & 19 & 71 \\
\% within group & $56.0 \%$ & $48.0 \%$ & $36.0 \%$ & $46.67 \%$ \\
\hline Grade IV Count & 14 & 0 & 0 & 14 \\
$\%$ Within & $28.0 \%$ & $0 \%$ & $0 \%$ & $9.33 \%$ \\
group & & & & \\
\hline Total Count & 50 & 50 & 50 & 150 \\
$\%$ within group & $100.0 \%$ & $100 \%$ & $100.0 \%$ & $100.0 \%$ \\
\hline
\end{tabular}

Chi-square $=23.846$ p $=.0005$ 
42 patients [84\%] in group MK had ideal conditions for venepucture compared to $24[48 \%]$ in group $\mathrm{M}$ and $19[38 \%$ ] in group $\mathrm{K}$. This yielded a $\mathrm{P}$ value of $<0.0005$ which is statistically very highly significant.

\section{Discussion}

Fear of surgery is common in every person irrespective of age. Anesthesiologist faces problem when a crying, uncooperative child is brought to operation room. There is no ideal premedication for pediatric age group. Purpose of our study was to determine whether addition of low dose ketamine to midazolam improves the efficacy of premedicant. Oral ketamine was first used in 1970s by dentist in mentally handicapped children. Then on different doses of ketamine have been tried in pediatric oral premedication. ${ }^{7,12}$ Administration of oral premedication in late half an hour or one hour prior to induction was shown to be effective and not associated with regurgitation or aspiration during induction. ${ }^{4}$ Intravenous ketamine administered is well known to cause side effects like hallucination, increased oral secretion, nystagmus etc. These side effects have been seen only with larger than usual doses of oral ketamine administration. ${ }^{13,14}$ Combination of oral ketamine and midazolam was first used by Lin et al in 1993. They used oral midazolam $0.5 \mathrm{mg} / \mathrm{kg}$ and ketamine $3 \mathrm{mg} / \mathrm{kg}$ dose combination. ${ }^{14}$

In our study midazolam in dose of $0.5 \mathrm{mg} / \mathrm{kg}$ was selected as this has proved to be safe premedicant in other studies. ${ }^{15}$ Ketamine $3 \mathrm{mg} / \mathrm{kg}$ was added to determine whether this further increased the efficacy of midazolam premedication. ${ }^{16-19}$ Funk et and Warner et al in their study observed better anxiolysis on separation from parents with combination of midazolam and ketamine than either of the drugs alone and the same is strengthened by our study result. ${ }^{18,19}$ We chose 30 minutes from administration of premedication to assess sedation and anxiety level, as previous studies have reported that 15 to 30 minutes time interval provided optimal efficacy of midazolam. ${ }^{6,20}$

In our study we found a significant improvement in sedation and anxiolysis with the combination than with midazolam or ketamine alone. Funk et al have reported similar results in their study. $80 \%$ of the children were calm and asleep at separation from parents at the end of $30 \mathrm{~min}$ in combination group. Our study correlates well with warner et al who showed $100 \%$ success rate at separation from parents in children sedated with ketamine and midazolam[18].Regarding venipuncture, venous cannulation was easily achieved and had more success rate in combination group (84\%) than in midazolam $(48 \%)$ or ketamine $(38 \%)$ alone. There wre no significant side effects or delay in recovery in any of the three groups of our study.

\section{Conclusion}

Oral premedication with combination of midazolam $0.5 \mathrm{mg} / \mathrm{kg}$, ketamine $3 \mathrm{mg} / \mathrm{kg}$ improves sedation, anxiolysis, allows better acceptance of parenteral separation, and venipuncture. So we suggest to add small dose of ketamine to oral midazolam premedication to take the benefits of both ketamine and midazolam.

\section{References}

1. Tan L, Meakin G H, Anaesthesia for the uncooperative child .Contin Educ Anaesth Crit Care Pain (2010), 10(2):48-52.

2. Singh N, Pandey R K, Saksena A K, Jaiswal J N. A comparative evaluation of oral midazolam with other sedatives as premedication in pediatric dentistry $\mathrm{J}$ Clin Pediatr Dent, 26 (2002), pp.161-4.

3. Sheta S A, Alsarheed M. Oral midazolam premedication for children undergoing general anaesthesia for dental care .Int J Pediatr, (2009), pp.:274-380.

4. Kazak Z, Sezer GB, Yilmaz AA, Ates Y. Premedication with oral midazolam with or without parental presence. Eur J Anaesthesiol. 2010 Apr;27(4):347-52.

5. Sen S, Thakurta RG, Gupta SD, Bhattacharya S, Mukherji S. Preoperative anxiolysis in pediatric population: A comparative study between oral midazolam and oral ketamine. Anesth Essays Res. 2013 MayAug;7(2):200-5. doi: 10.4103/0259-1162.118960.

6. Darlong V, Shende D, Singh M, Garg R, Pandey R, Punj J. Low- versus high-dose combination of midazolamketamine for oral premedication in children for ophthalmologic surgeries Singapore Med J. 2011 Jul;52(7):512-6. Erratum in: Singapore Med J. 2011 Sep;52(9):704.

7. Sekerci C, Dönmez A, Ateş Y, Okten F. Oral ketamine premedication in children (placebo controlled double blind study). Eur J Anaesthesiol. 1996 Nov;13(6):606-11.

8. Malinovsky JM, Servin F, Cozian A, Lepage JY, Pinaud $M$. ketamine and norketamine plasma concentrations after i.v. nasal and rectal administration in children. $\mathrm{Br} \mathbf{J}$ Anaesth.1996 Aug;77(2):203-7.

9. Malinovsky JM, Lejus C, Servin F, Lepage JY, LeNormand $Y$, Testa $S$ et al. Plasma concentrations of midazolam after i.v., nasal or rectal administration in children. Br J Anaesth. 1993,Jun;70(6):617-20.

10. Abdallah C, Hannallah R. Premedication of the child undergoing surgery. Middle east $\mathbf{J}$ Anaesth.21(2),2011;165-74.

11. Kain ZN, Mayes LC, Bell C, Weisman S, Hofstadter MB, Rimar $S$ Premedication in the United States: A status report. Anesth Analg. $1997 \mathrm{Feb} ; 84(2): 427-32$.

12. Gutstein HB, Johnson KL, Heard MB, Gregory GAOral ketamine preanesthetic medication in children. Anesthesiology. 1992 Jan; 76(1):28-33.

13. Donahue P J, Dineen P S, .emergence delirium following oral ketamine Anesthesialogy, 1992;77:604-5.

14. Lin Y C, Moynihan R J, Hackel A. A comparison of oral premedication with midazolam, ketamine and combination in pediatric patients. Anaesthesiology.1993;70:1177-79.

15. Weldon B C . Oral midazolam in children. Effect of time and adjunctive therapy. Aneth Analg1992;75:51-5.

16. Astuto M, Disma N, CrimiE.Two doses of oral ketamine given with midazolam for premedication in children. Journal of oral maxillofacial surgery1996.;6:54;838-44. 
17. Roelofse J A, Louw L R, Roelfose P G. sedation in pediatric dental patients with midazolam alone and midazolam combined with ketamine. Br J of A naes2000(3);84;335-40.

18. Warner D L, Cabaret J, Velling D. ketamine and midazolam , a most effective oral premedicant. Can J of Anaesthesia 1993(8),40;726-29.

19. Funk W, Jakob W, Riedel T. Oral premedication with combination of midazolam and ketamine vs midazolam or ketamine alone. Br Jr of Anaes.2000;84:335-40.

20. McMilan C O, Spahr-Schopfer I A, Sikich N, Hartley E. Premedication of children with oral midazolam.Can J of Anaesthesia 1992;39:545-50. 